\title{
Rehabilitation of endodontically treated tooth with anatomic post and core: A novel approach
}

\author{
Swapnil V Chandekar, Shishir H Singh, Rajesh S Podar, Shashank N Babel and Jinal J Shah \\ Tpct's Terna Dental College and Hospital, Phase II, Sector - 22, Nerul (W), Navi Mumbai - 400706 Maharashtra, India
}

\begin{abstract}
The introduction of fiber posts has a great impact on the clinical procedures on restoring endodontically treated teeth. Endodontically treated teeth with severe coronal destruction have been a very common clinical procedure in the restorative clinical practice. This translucent fiber post is covered by a layer of light cured resin which allows for an individual anatomical modelling of the post through its insertion in root canal with the aim of achieving a better adaptation, retention. In this way, the combination of two restorative materials (compound resin and post) will serve and behave biomechanically as a replacement for the lost dentin structure. The aim of this clinical case report is to exhibit the preparation of anatomical post by using composite resin and fiber-glass posts on upper right central incisor with weakened root, with the objective of reinstate the coronal portion of the tooth.
\end{abstract}

\section{Introduction}

The introduction of fiber posts has a great impact on the clinical procedures on restoring endodontically treated teeth. There has been continuous research on these products to modify the type of fibers from (carbon to quartz to glass) as well as the shape of the posts. Endodontically treated teeth with severe coronal destruction have been a very common clinical procedure in the restorative clinical practice. With this type clinical situation, there will be a prominent need for use of intraradicular retainers to obtain greater stability and retention of the restoration to the remaining teeth $[1,2]$.

The restorative technique known as an anatomical post is proposed for the rehabilitation of anterior teeth with extensively compromised root canal and with significant removal of dentin tissue [3].

This translucent fiber post is covered by a layer of light cured resin which allows for an individual anatomical modelling of the fiber post through its insertion in root canal with the aim of achieving a better adaptation, and retention. In this way, the combination of two restorative materials (compound resin and post) will serve and behave biomechanically as a replacement for the lost dentin structure [4].

The anatomical posts have an extremely favourable prognosis in cases of fragile roots due to loss of dentin structure and they contribute significantly to the rehabilitation of the tooth both in the aspect of the masticatory function and in aesthetics [5].

In addition, the glass fiber posts have a more uniform distribution of tension in the occlusal and radicular region when compared with metal posts [6].

The aim of this clinical case report is to exhibit the preparation of anatomical post by using composite resin and fiber-glass posts on upper right central incisor with weakened root, with the objective of reinstate the coronal portion of the tooth.

\section{Case report}

An eighteen-year-old male patient reported to Department of Conservative Dentistry and Endodontics, Terna Dental College \&
Hospital with chief complain of fractured tooth in upper anterior tooth region.

On complete clinical examination patient presented with

1. Complicated crown fracture with upper right central incisor and mesial mobile segment with no pain on percussion test (Figures 1 and 2).

2. On pulp vitality test - there was no response to cold and electric pulp test.

Prognosis of endodontic treatment and anatomical post was proposed to the patient, in order to recover the function and aesthetics of the tooth and provide for future rehabilitation of the tooth with a full ceramic crown.

Under all aseptic conditions anterior superior alveolar nerve block (ASA) \& incisive nerve block was injected. The mesial mobile segment was extracted, and complete caries excavation was done followed by endodontic procedure with the aim of satisfactory Endodontic treatment.

With the aim of coronal dentin conservation, access opening was done with safe end tapered fissure carbide bur (ESE-018). Working length determination was done with apex locator (ProPex Pixi, Dentsply Sirona \& Maillefer) and radiographic method $(22 \mathrm{~mm})$. Root canal preparation was done by K-hand files (Mani, Inc, Japan) by step back technique up to size \#120. Desired master cone (70/2) was evaluated prior to obturation, and obturation was done by warm lateral compaction technique (Figures 3-5).

*Correspondence to: Swapnil V Chandekar, Tpct's Terna Dental College and Hospital, Phase II, Sector - 22, Nerul (W), Navi Mumbai - 400706 Maharashtra, India, Tel: 9096829313, E-mail: swapnilchandekar53@gmail.com

Key words: glass fiber post, anatomic post, post and core, adaptation, retention

Received: October 18, 2018; Accepted: November 07, 2018; Published: November 12, 2018 


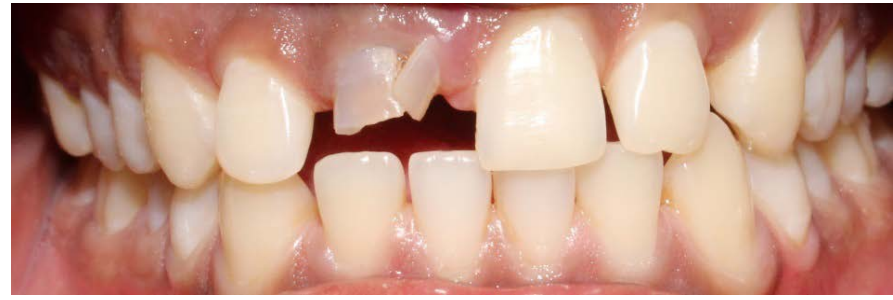

Figure 1. Labial aspect

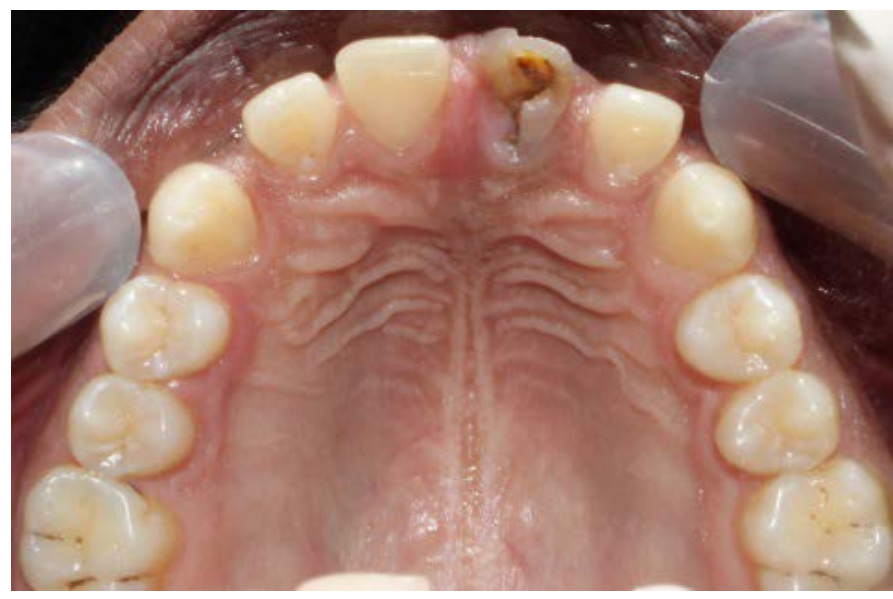

Figure 2. Palatal aspect

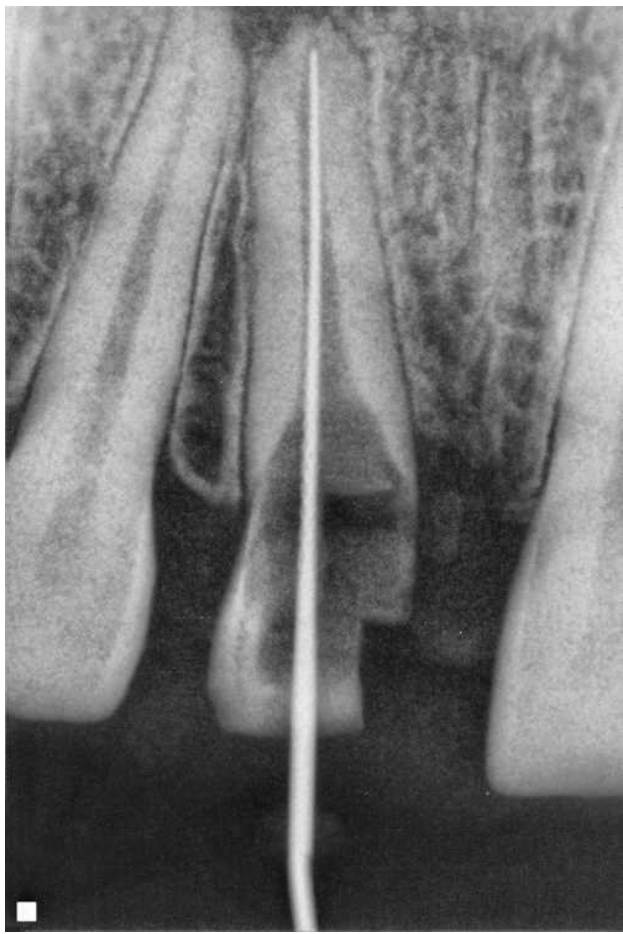

Figure 3. Working length

After endodontic treatment post space preparation was done with largo burs size \# 1,2 up to $18 \mathrm{~mm}$ of canal working length (Figure 6).

After the post space preparation desired fiber post was selected \#2 (Medicept, Selfpost, glass fiber post) and layering on fiber post was done in increments with packable composite resin, in order to replicate the anatomic from of root canal with photo activation, (curing cycle of
$20 \mathrm{sec}$ for each increment) then the anatomic post was gently pulled out of the canal and additional light curing of $20 \mathrm{sec}$ was performed in order to completely polymerize relining resin (Figures 7-11).

Clinically the coronal tooth structure was compromised so in order to achieve final tooth restoration with sound tooth margins, clinical crown lengthening procedure was carried out in Dept. of Periodontics \& Implantology Terna Dental College \& Hospital (Figures 12 and 13).

On periodontal examination inadequate crown height and $1 \mathrm{~mm}$ of gingival sulcus depth was with upper right central incisor and on transgingival probing the depth was $2 \mathrm{~mm}$. Because of which osseous reduction was done to maintain the biologic width.

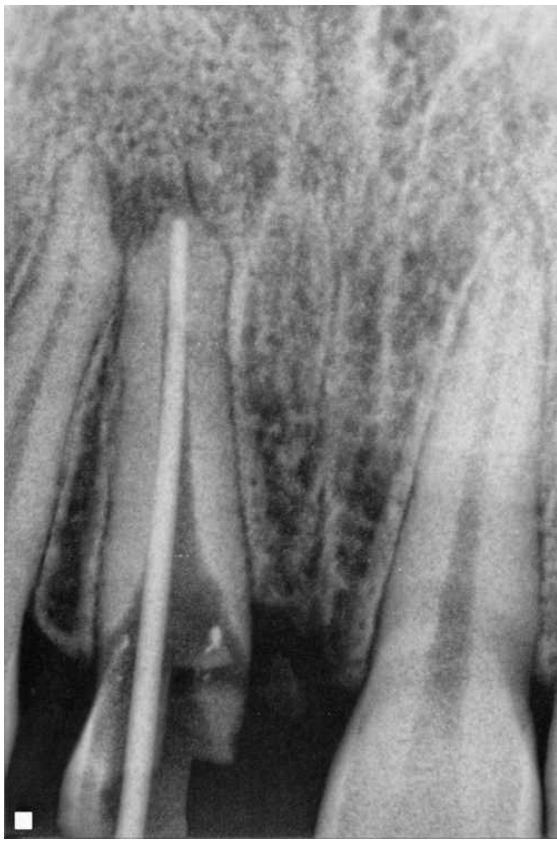

Figure 4. Master cone

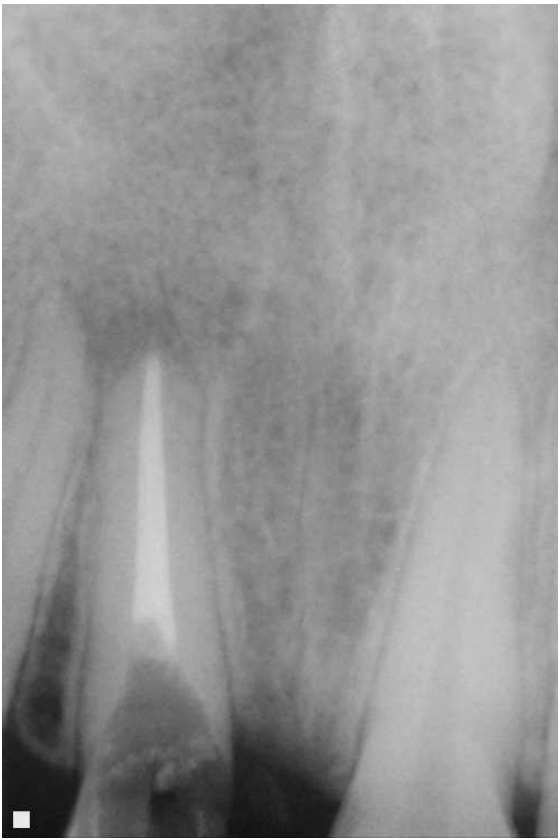

Figure 5. Obturation 


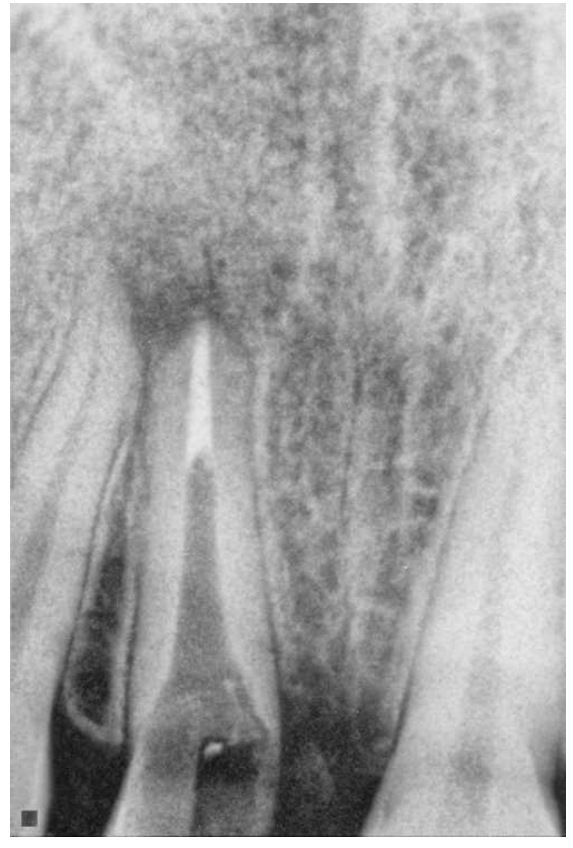

Figure 6. Post space preparation
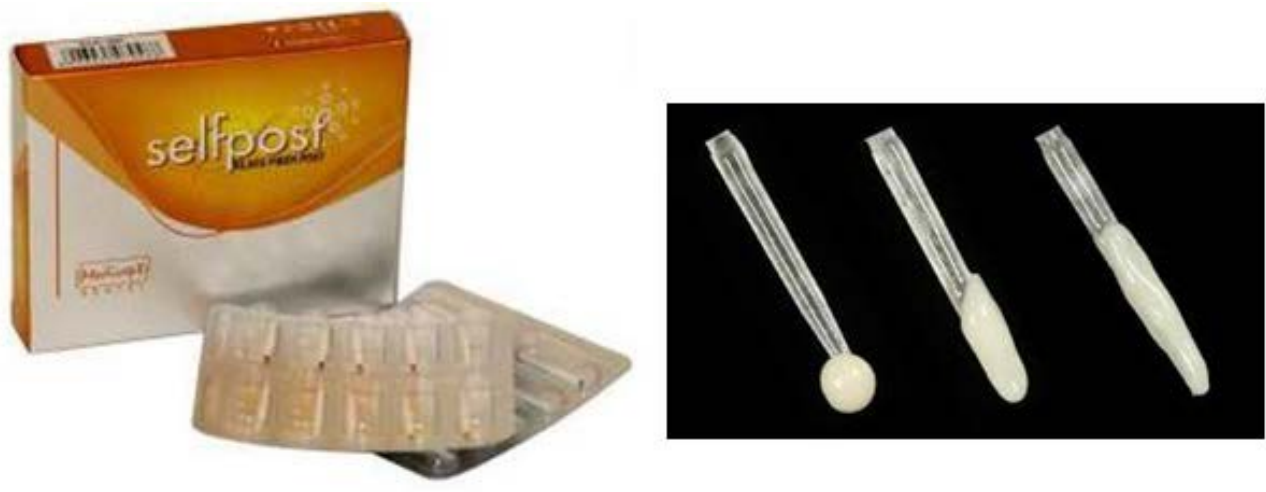

Figure 7. Medicept, Self- post, glass fiber post and layering of fiber post by resin increments
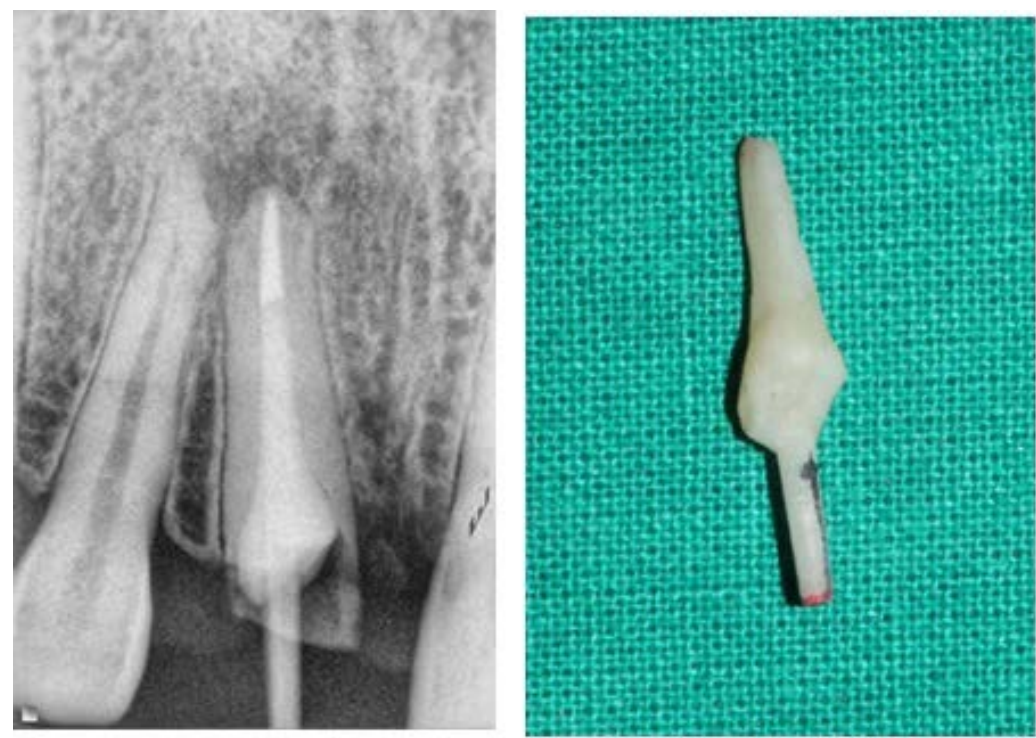

Figure 8. Radiographic and clinical appearance of anatomic post 

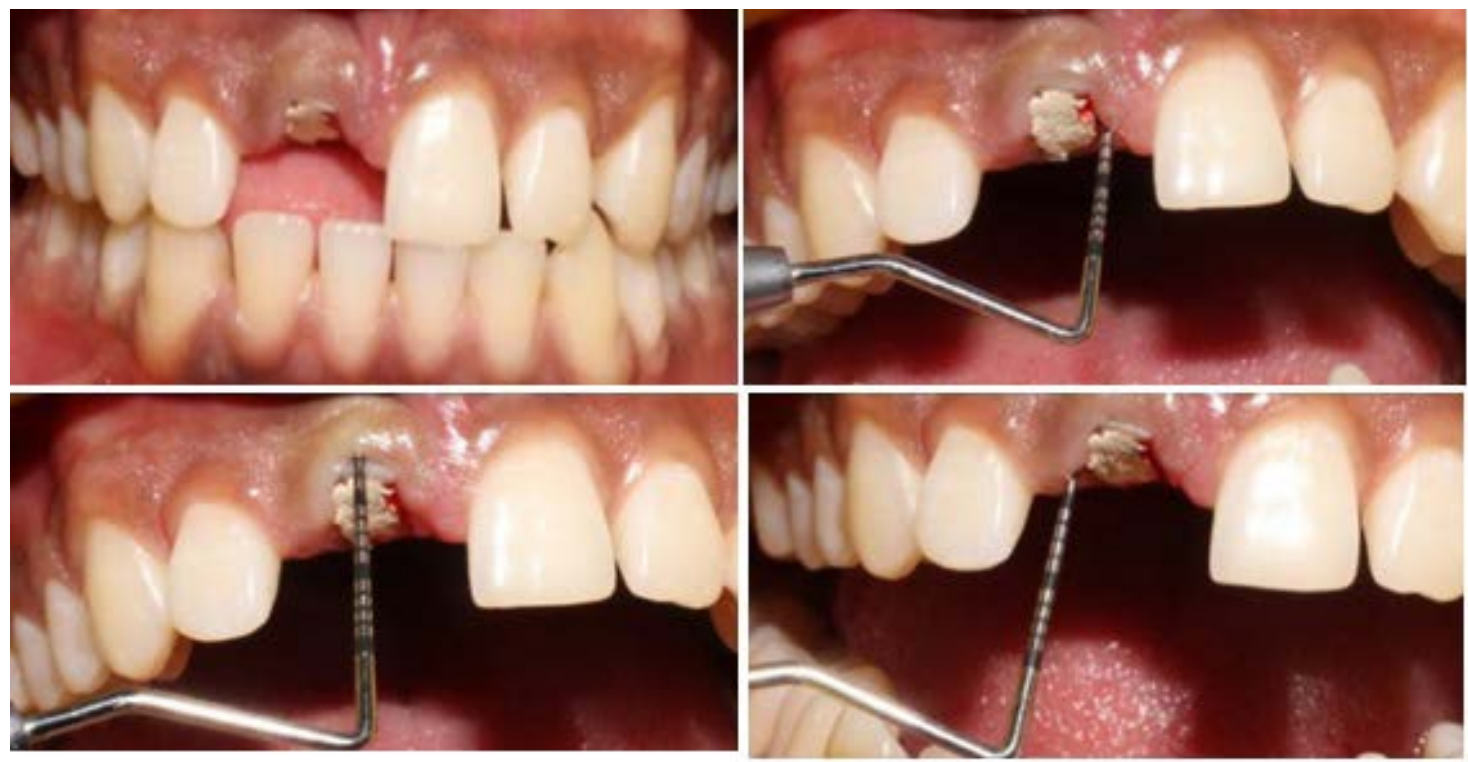

Figure 9. Pre-operative required length for CLP
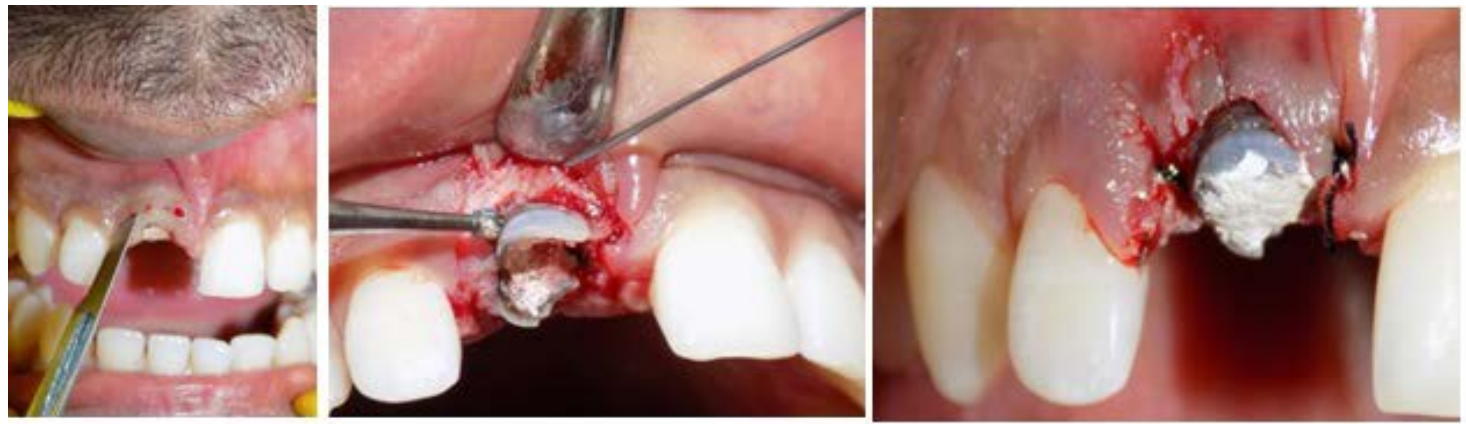

Figure 10. Clinical crown lengthening procedure

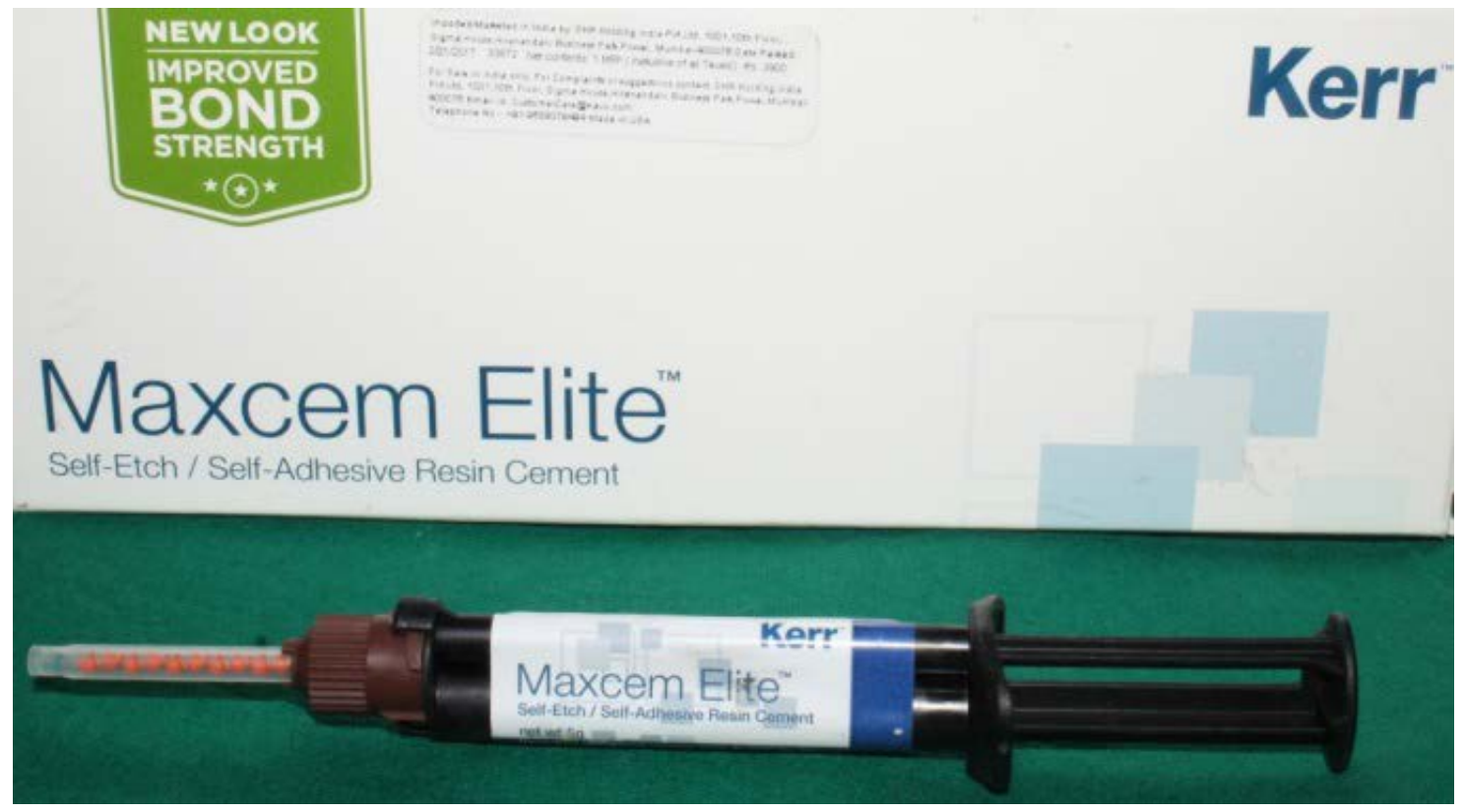

Figure 11. Maxcem Elite self-etch, self-adhesive resin cement (kerr) 


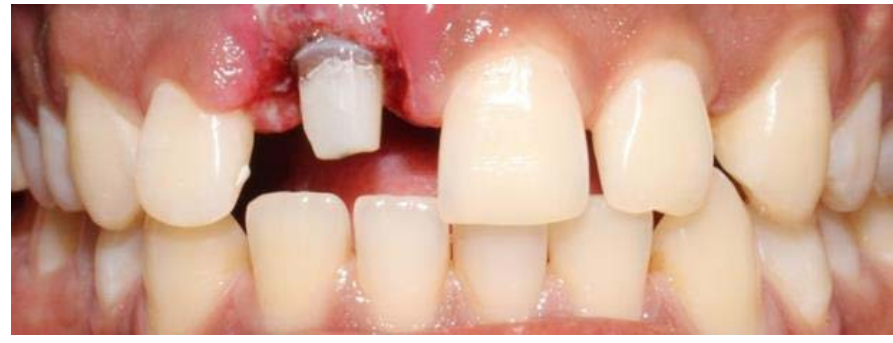

Figure 12. Prosthetic preparation of the core

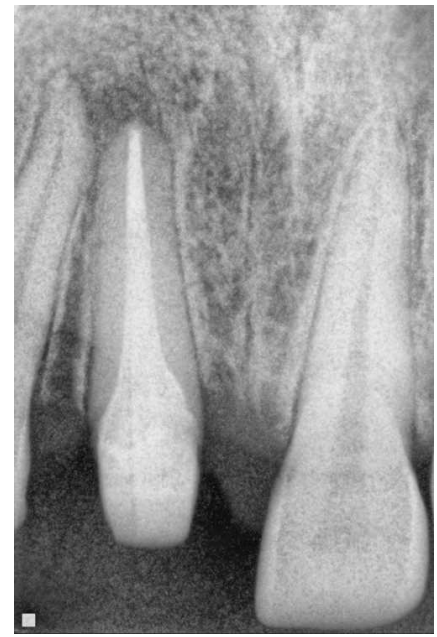

Figure 13. Final radiographic appearance glass fiber post and core

Under local anaesthesia with adrenaline 1:80000 bleeding points were marked at $2 \mathrm{~mm}$ from gingival margin. External bevel incision followed by crevicular incision was taken and $2 \mathrm{~mm}$ of gingival tissue was excised. Flap was raised, and $3 \mathrm{~mm}$ osseous reduction was done followed by placement of interdental sutures, and COE pack was placed.

After one-week patient was recalled for suture removal and for core build up. Maxcem Elite self-etch, self-adhesive resin cement (kerr) was mixed according to manufacturer instructions and dispensed and luted over the anatomic post. Excess cement was removed, and photo activation of anatomic post was done for $20 \mathrm{sec}$.

After the luting of post, coronal reconstruction was done with the same composite resin in incremental portions and followed by photo activation of each increment for $20 \mathrm{sec}$. To complete the restorative manifesto, the prosthetic preparation of the core was done for future execution of a full ceramic crown with diamond burs.

And afterwards addition silicon impression was made (DMG silagum, Hamburg, Germany) of prepared tooth surface and irreversible hydrocolloid impression was made for lower arch (Figure 14).

Type IV die stone was poured, and the casts were mounted on a semiadjustable articulator. Patient was recalled for the next appointment after 3 days. The All ceramic crown was evaluated intraorally to assess marginal fit and aesthetics before definitive cementation procedures. The resin cement (Maxcem Elite, self-etch, self-adhesive resin cement, kerr) was applied on the cementation surface of crown, Then, the crown was placed on the desired tooth, by paying attention to achieve full seating using finger pressure. Further a thin explorer was used to remove excess luting material extruded from the crown margins and then photo activation of all ceramic crown was done for $(40 \mathrm{sec})$ on labial and palatal aspect (Figures 15-18)
Diamond burs and polishing discs were used to reduce high points and followed by interproximal flossing Static and dynamic occlusions were checked. The patient was recalled after 3 weeks for re-checking for occlusion, proximal contact relationships, marginal integrity, and gingival margin health.

\section{Discussion}

Teeth submitted to endodontic treatment typically have extensive loss of dental structure and requires the use of intraradicular retainers and filling cores to hold the final restoration [7].

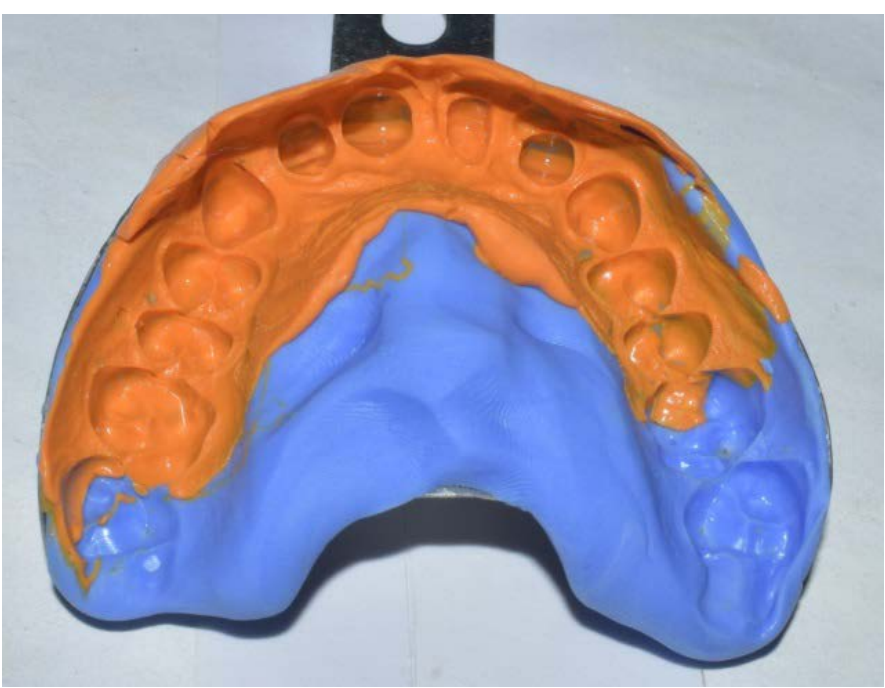

Figure 14. Addition silicon Impression

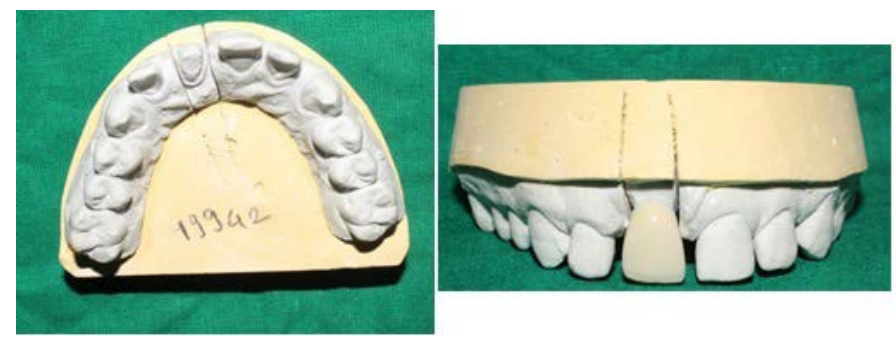

Figure 15. Final master cast with crown prosthesis

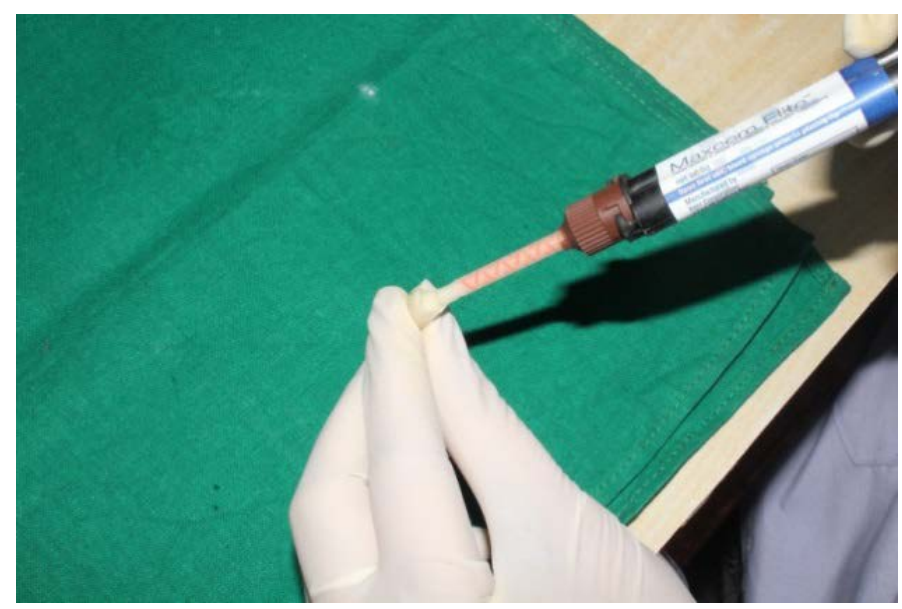

Figure 16. Cementation of crown prosthesis 


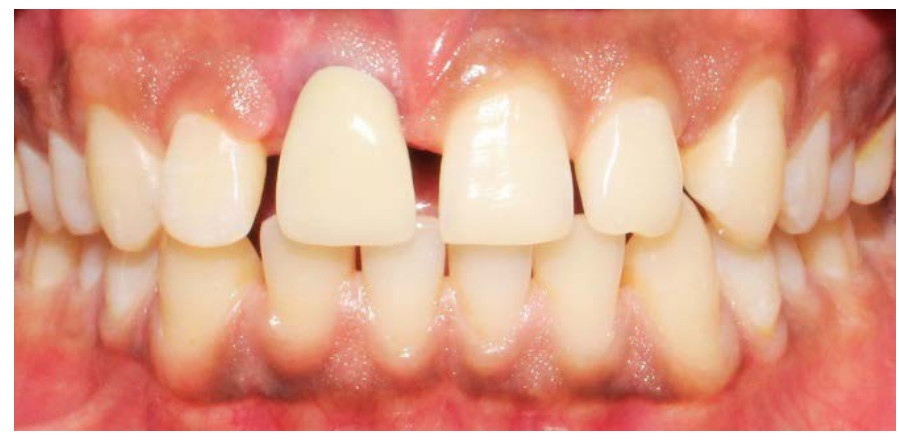

Figure 17. Post-operative view

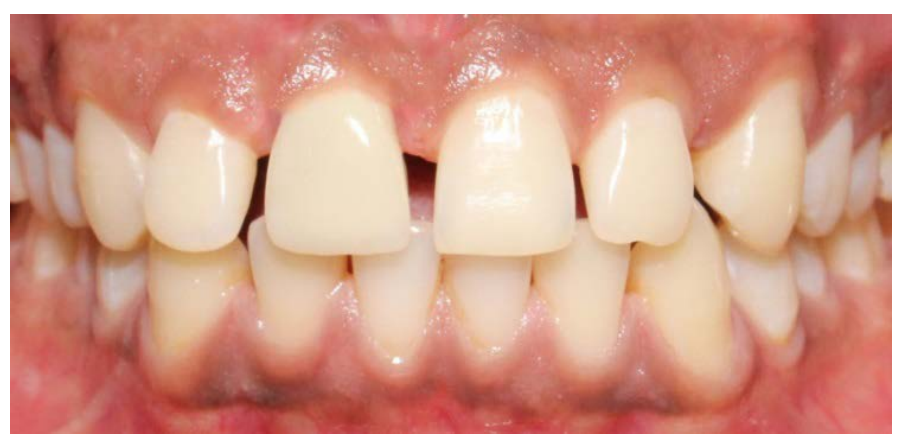

Figure 18. One year follow up

Cast-metal cores can be made to adapt well to the remaining root structure, they can produce a wedging action under masticatory forces, resulting in root fractures and condemning the tooth to extraction [8].

Prefabricated fiber posts do not resemble the individual root canal anatomy and adapt inaccurately, thereby obliging the operator to employ excessive amounts of resin cement to replace lost structure [9]. In this way, several techniques have been suggested to restore weakened root canals, and among them, there is the technique of anatomical shaping of prefabricated fiber posts with a composite resin into the root canal [10]. This technique provides a close adaptation of the post to the root canal, reduces the resin cement thickness, improves the mechanical and retentive properties of restored teeth and significantly reduces the chance of root fracture [11].

The present case was suitable for the preparation of a direct anatomic post. The tooth had a flared root canal with thin radicular dentin. Introducing a conventional fiber post into the canal required a thick layer of luting cement to fill up the spaces between the loosely fitting post and the canal walls. This would have subjected the restoration and tooth to adhesive failure and/or post debonding [12]. Thus, using a post well-fitted to the canal shape allows the use of a thin, uniform layer of cement that increases retention.

In the direct anatomical post technique, as performed in this case report, the fiber post is relined in the root canal, replacing the resin cement with composite resin, which has better mechanical and physical properties. This technique is relatively easy; only a few additional steps are required beyond those needed to lute a conventional fiber post [13].

The good performance of the anatomical post techniques in laboratory studies can be attributed to the high hydraulic pressure they put on the cement against the dentin walls, resulting in better contact between the cement/post set and the dentin. This pressure reduces blister formation in the cement, eliminating sources of flaw-initiating sites; increases the number of tubules filled with the resin cement because of better penetration of resin into demineralized dentin and results in a more uniform hybrid layer, with greater resin tags and adhesive lateral branches [14].

\section{Conclusion}

The anatomical post constituted a clinical alternative for coronal and radicular reconstruction on endodontically treated teeth with significant destruction of dentin tissue. In addition to rehabilitating the tooth, this clinical proposal promotes a more balanced distribution of tensions from mastication without compromising the remaining tooth, minimizing the risks of radicular fracture.

One of the most important factors that this restorative alternative provides is the possibility for an aesthetic result with the use of a metalfree full crown.

\section{Acknowledgment}

I would like to acknowledge Dr Shishir Singh, Dean, Terna Dental College, Navi Mumbai and all co-authors for their guidance in completing this case effectively. In addition to this, all the co-authors mentioned have made a significant contribution to this case report with regard to the write-up and its correction

\section{Conflict of Interest}

No potential conflict of interest relevant to this article was reported.

\section{References}

1. Torabi K, Fattahi F (2009) Fracture resistance of endodontically treated teeth restored by different FRC posts: an in vitro study. Indian J Dent Res 20: 282-287. [Crossref]

2. Hattori M, Takemoto S, Yoshinari M, Kawada E, Oda Y (2010) Durability of fiber-post and resin core build-up systems. Dent Mater J 29: 224-228. [Crossref]

3. Clavijo VG, Reis JM, Kabbach W, Faria e Silva AL, Oliveira Junior OB, et al. (2009) Fracture strength of flared bovine roots restored with different intraradicular posts. $J$ Appl Oral Sci 17: 574-578. [Crossref]

4. Zicari F, Couthino E, De Munck J, Poitevin A, Scotti R, et al. (2008) Bonding effectiveness and sealing ability of fiber-post bonding. Dent Mater 24: 967-977. [Crossref]

5. Perdigão J, Gomes G, Augusto V (2007) The effect of dowel space on the bond strengths of fiber posts. J Prosthodont 16: 154-164. [Crossref]

6. Grandini S, Sapio S, Simonetti M (2003) Use of anatomic post and core for reconstructing an endodontically treated tooth: a case report. $J$ Adhes Dent 5: 243-247. [Crossref]

7. Heydecke G, Butz F, Strub JR (2001) Fracture strength and survival rate of endodontically treated maxillary incisors with approximal cavities after restoration with different post and core systems: An in-vitro study. J Dent 29: 427-433. [Crossref]

8. Faria-e-Silva AL, Pedrosa-Filho Cde F, Menezes Mde S, Silveira DM, Martins LR (2009) Effect of relining on fiber post retention to root canal. J Appl Oral Sci 17: 600604. [Crossref]

9. Gomes GM, Rezende EC, Gomes OM, Gomes JC, Loguercio AD, et al. (2014) Influence of the resin cement thickness on bond strength and gap formation of fiber posts bonded to root dentin. J Adhes Dent 16: 71-78. [Crossref]

10. Bonfante G, Kaizer OB, Pegoraro LF, do Valle AL (2007) Fracture strength of teeth with flared root canals restored with glass fibre posts. Int Dent J 57: 153-160. [Crossref]

11. Goncalves LA, Vansan LP, Paulino SM, Sousa Neto MD (2006) Fracture resistance of weakened roots restored with a transilluminating post and adhesive restorative materials. J Prosthet Dent 96: 339-344. [Crossref]

12. Yoldas O, Alacam T (2005) Microhardness of composites in simulated root canals cured with light transmitting posts and glass-fiber reinforced composite posts. $J$ Endod 31: 104-106. [Crossref] 
Chandekar SV (2018) Rehabilitation of endodontically treated tooth with anatomic post and core: A novel approach

13. Zogheib LV, Pereira JR, do Valle AL, de Oliveira JA, Pegoraro LF (2008) Fracture resistance of weakened roots restored with composite resin and glass fiber post. Braz Dent J 19: 329-333. [Crossref]
14. Grandini S, Goracci C, Monticelli F, Borracchini A, Ferrari M (2005) SEM evaluation of the cement layer thickness after luting two different posts. $J$ Adhes Dent 7: 235-240. [Crossref]

Copyright: (C2018 Chandekar SV. This is an open-access article distributed under the terms of the Creative Commons Attribution License, which permits unrestricted use, distribution, and reproduction in any medium, provided the original author and source are credited. 